\title{
ESWIRP: European Strategic Wind tunnels Improved Research Potential program overview
}

\author{
Guy Boyet $^{1}$ (D)
}

Received: 22 September 2016 / Revised: 7 March 2018 / Accepted: 16 April 2018

(c) Deutsches Zentrum für Luft- und Raumfahrt e.V. 2018

\begin{abstract}
"European Strategic Wind tunnel Improved Research Potential" ESWIRP was a project in the EU 7th Framework Program (FP7-Grant agreement no: FP7-227816), which was aiming at improving the performance capabilities of three strategic wind tunnels in Europe, by strengthening the cooperation between these wind tunnels in a new consortium. The research consortium members are Office National d'Etudes et de Recherches Aérospatiales (operating the S1MA as its largest sonic wind tunnel), German-Dutch wind tunnels [operating the large low-speed facility (LLF) as its largest low-speed wind tunnel], and European transonic wind tunnel (ETW) (operating its cryogenic wind tunnel). Together, these wind tunnels cover a wide range of experimental capabilities of relevance to civil aviation and aeronautical research in general. The project started in October 2009 for a period of 5 years. The European financial contribution was $€ 7.2$ million. The project consist of two major parts: (1) improvements to the testing infrastructure; and (2) the provision of wind tunnel access to research groups which do not usually have the means to access such large-scale test facilities. These topics also involved public dissemination and information activities. Although the tunnels covered in this project are of a complementary nature, the infrastructure activities were joined together, by a common representation of, and approach to, the tunnel performance characteristics. To this end, a generic model of a virtual wind tunnel was developed, enabling operators to assess the effect of the control parameters upon the testing conditions. The final aim of all participants was to provide the user community with an improved set of capabilities to test their innovative ideas. To provide better access to these three major wind tunnels, mainly research groups from European universities were contacted. The approach taken has included maximum transparency of the process and support of the researchers by the organizations responsible for the tunnels. In addition, when possible, we encouraged research groups to work together, to obtain the full benefit of economies of scale in research projects. ESWIRP responded to the targeted approach of the Integrating Activities of the FP7 Capacities Work Program: Networking activities, essentially focused around four topics: (1) organization of information campaigns, lectures and workshops to disseminate knowledge between the partners and future users. (2) Opening of a website for the consultation of wind tunnel standards. (3) Exchange of personnel between the Consortium partners, to foster the spread of good practices and the exchange of technical know-how. (4) Joint development of a reference wind tunnel parameter database. Trans-national access and/or testing services: after the call for proposals by the facility providers, groups of researchers had the opportunity to benefit from free wind tunnel services, including technical assistance to support the corresponding scientific research team(s). Joint research activities, innovative modeling of wind tunnels has helped designers to make better decisions, before the implementation of any novel hardware. Based on a generic finite volume type of modeling approach, the operational behaviour and the time-dependent flow quantities around the wind tunnel circuit have been simulated. Such model can be used, for example, to conceive and tune particular sub-system control laws, or explore the implications of hardware changes. Based on a common approach, dedicated models were developed for S1MA, LLF and ETW. The infrastructure improvements targeted the capability to obtain unsteady test data (with high accuracy) in the ETW, to improve the capability to simulate aircraft behaviour in ground effect in the LLF, and to establish a reliable closed-loop control of test Mach number in the S1MA wind tunnel. European Strategic Wind tunnels Improved Research Potential Program is European support for strategic wind tunnels, key research infrastructures in the development process of current and future aircraft. This is the first time that European authorities have given such support.
\end{abstract}

Extended author information available on the last page of the article 


$\begin{array}{ll}\text { Abbreviations } \\ \text { AVS } & \text { Anti-vibration system } \\ \text { CFD } & \text { Computational fluid dynamics } \\ \text { CRM } & \text { Common research model } \\ \text { CS } & \text { Clock synchronization } \\ \text { CUs } & \text { Conditioning units } \\ \text { DAU } & \text { Data acquisition unit } \\ \text { DNW } & \text { German-Dutch wind tunnels } \\ \text { EAR } & \text { "Entrée d'Air de Régulation" (additional air } \\ & \text { inlet for Mach number regulation) } \\ \text { ETW } & \text { European transonic wind tunnel } \\ \text { ESWIRP } & \text { European Strategic Wind tunnels Improved } \\ & \text { Research Potential Program } \\ \text { FP7 } & \text { 7th Framework Program } \\ \text { GFN } & \text { Glass-fibre network } \\ \text { LLF } & \text { Large low-speed facility } \\ \text { MBGP } & \text { Moving belt ground plane } \\ \text { NAS } & \text { Network attached storage } \\ \text { NLR } & \text { Netherlands aerospace centre } \\ \text { ONERA } & \text { Office National d'Etudes et de Recherches } \\ & \text { Aérospatiales } \\ \text { PIV } & \text { Particle image velocimetry } \\ \text { SRV } & \text { Swirl recovery vanes } \\ \text { TNA } & \text { Trans-national access } \\ \text { TR-PIV } & \text { Time-resolved particle image velocimetry } \\ \text { TSP } & \text { Temperature sensitive paint } \\ \text { U-DAS } & \text { Unsteady data storage } \\ \text { UDAS } & \text { Unsteady data acquisition system } \\ & \end{array}$

\section{Introduction}

"European Strategic Wind tunnels Improved Research Potential" ESWIRP was a project in the EU 7th Framework Program (FP7-Grant agreement FP7-227816), which was aiming at improving the performance capabilities of three strategic wind tunnels in Europe, by strengthening the cooperation between these wind tunnels in a new consortium. The research consortium members were Office National d'Etudes et de Recherches Aérospatiales (ONERA) (operating the S1MA as its largest sonic wind tunnel), DNW (operating the LLF as its largest low-speed wind tunnel), and ETW (operating its cryogenic wind tunnel). Together, these three wind tunnels cover a wide range of experimental conditions of relevance to civil aviation and aeronautical research in general.

\section{Three European strategic wind tunnels}

\subsection{ONERA S1MA wind tunnel}

The ONERA S1MA wind tunnel facility is a closed circuit atmospheric wind tunnel with a maximum speed near
Mach 1, which provides unique capabilities for testing large airliner models at cruising speed and above. The tunnel is located near Modane, France, and was erected after the Second World War. The tunnel has three exchangeable test sections with a uniquely large diameter of $8 \mathrm{~m}$, which can be transformed into five different test section configurations. The benefit of having large models is essential for testing new concepts, and having enough room within the models for housing various devices, such as boundary layer control devices, remotely actuated mechanisms, drag reduction devices; aircraft control mechanisms for both handling qualities and efficiency improvement, and laminar flow concepts.

Civil transport aircraft developed over the last decades have been designed with a consistently increasing maximum cruise speed. The benefits retrieved from experimental work performed at S1MA are essential for future high-speed research. The S1MA represents a strategic facility which must be closely looked at, in terms of capabilities to fulfil the increasing complex requirements of it's users.

The design of the next generation of aircraft will be strongly influenced by environmental impact considerations. Future aircraft configurations will be based on a compromise between fuel consumption reduction, low noise levels (cabin noise and noise nuisances to the surroundings) and performance. The trade-off between various options at high speed will ideally be determined at S1MA, which already has a long-term experience with motorized models, using high-pressure air to study engine installation effects. In this respect, the accumulated experience with testing propeller driven aircraft in S1MA, will serve well for testing future rear-mounted open-rotor configurations, for instance.

The large S1MA facility is essential to aircraft manufacturers worldwide and also to a number of researchers, who take benefit of its large size, and hence associated large model scales, which allow very innovative ideas to be tested.

Amongst the leading criteria to use S1MA are:

- Its large-scale capabilities.

- Its access cost.

- Its availability.

The ESWIRP project objectives for S1MA are to save $30-35 \%$ of the time necessary for an experiment, by providing improved quality data with no necessity to repeat data acquisition. This will have a double impact:

- Better quality of the data provided to our customers, because the aerodynamic parameters will be acquired in perfectly stable conditions.

- Possibility to test more new research ideas and concepts for a given budget. 


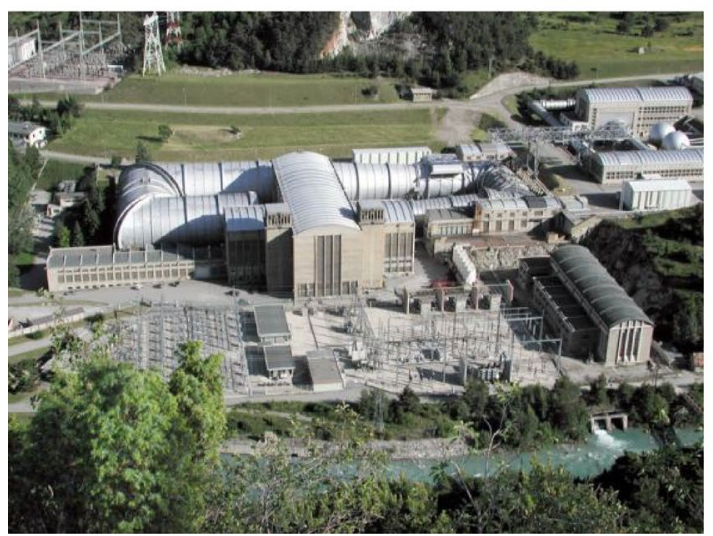

Overview of the S1MA wind tunnel

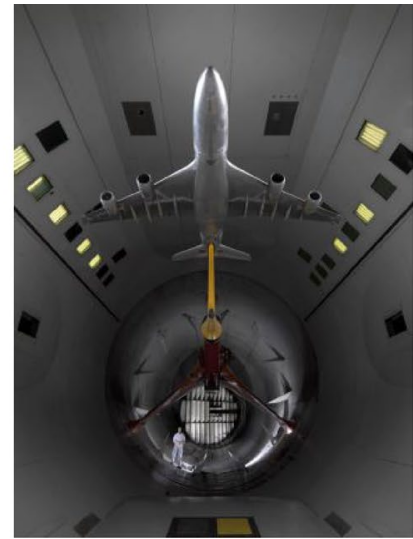

ONERA S1MA test section

Diameter 8 meters

Length 14 meters

\subsection{Large low-speed facility DNW-LLF}

The DNW-LLF is a closed circuit low-speed wind tunnel with a maximum speed near Mach 0.4. The tunnel is located near Marknesse in the Netherlands. The tunnel has been in operation since 1980. The LLF has two interchangeable test sections of $9.5 \mathrm{~m} \times 9.5 \mathrm{~m}$ and $6 \mathrm{~m} \times 8 \mathrm{~m}$ (height $\times$ width), respectively, with which four test section configurations (including open jet) can be realized. The LLF has an internal balance sting system for model support, and is further equipped with a moving belt ground plane (MBGP) with a maximum speed of $40 \mathrm{~m} / \mathrm{s}$. The MBGP is provided with a boundary layer removal system that scoops and re-injects the floor boundary layer air into the tunnel circuit. The demand for further improvements in aircraft fuel efficiency, as well as for the reduction of noise around airports, makes an upgrade of the facility a necessity. Since landing and takeoff phases of the aircraft flight have a major effect on the population, the availability of the best possible experimental simulation capabilities for this phase of flight are essential for progress. In particular, the quality of the tunnel air flow and ground simulations are an integral part in providing data in the exploration of new possibilities.

The proposed technical upgrade of the LLF in the framework of ESWIRP foresaw major improvements on the existing MBGP. Higher relative speeds than achieved today, were targeted. Therefore, the quality of the simulation of the relative motion between an aircraft and the runway becomes higher, and consequently a considerable increase in data reliability can be reached.

ESWIRP opened the possibility to initiate joint research activities with the Consortium partners to study the impact of the planned upgrade on flow simulation, to prepare the detailed design, and to familiarize the aeronautics research community with the improvements in potential obtainable design from improved ground simulation.

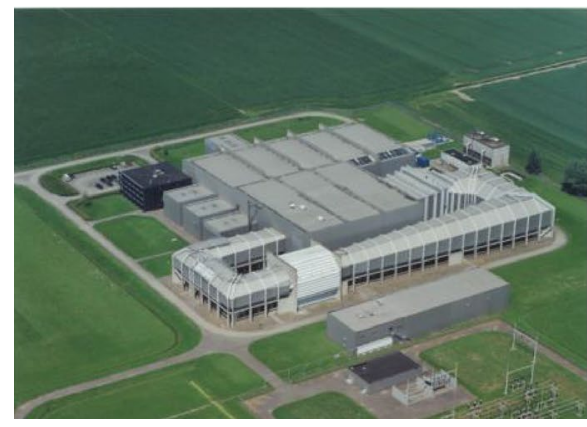

Overview of the DNW-LLF wind tunnel

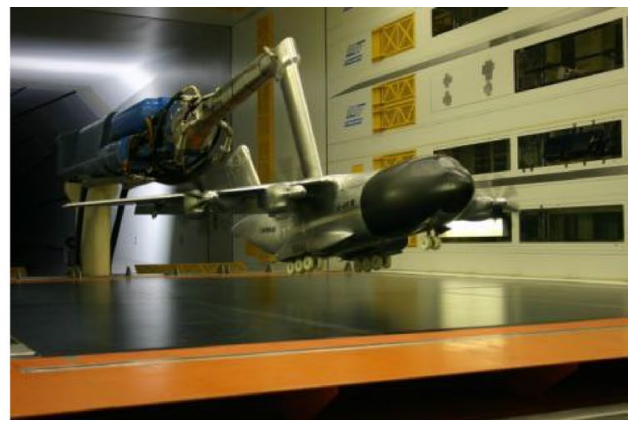

LLF test section

$8 \times 6$ meters

ground effect test setup 


\subsection{Cryogenic wind tunnel ETW}

The ETW uniquely achieves real-flight Mach and Reynolds numbers for transport aircraft at model scale. This unique capability is achieved by cryogenic pressurized operation of the wind tunnel from low speed up to Mach 1.35 using Nitrogen gas. With ETW, researchers are able to check scientific concepts for applicability at real-flight conditions, effectively and efficiently at low risk. Therefore, ETW contributes to increased aeronautical innovation speed, and enables research to provide breakthrough technologies for ecological and economical optimization of future air transport. flight envelope boundary of an aircraft, and hence better understanding and control of this phenomenon is the subject of on-going aeronautical research. Compared with CFD and conventional wind tunnels, the ETW wind tunnel capabilities allow the study of these phenomena at flight conditions.

The improvements made through ESWIRP, enable researchers to make better use of these capabilities due to the increased flexibility in tunnel access. The making available of tools for unsteady force and moment investigations up to real-flight conditions, has additionally opened up a new unique area of wind tunnel testing.

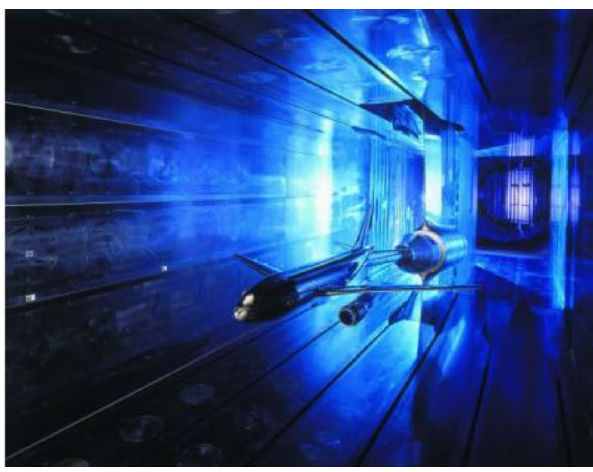

ETW cryogenic test section $2.4 \times 2$ meters and 9 meter length
The ETW has been in operation since 1994. Its test section dimensions are $2.0 \mathrm{~m} \times 2.4 \mathrm{~m}$ (height $\times$ width). The test medium nitrogen gas can be pressurized up to 4.5 bar and used at a cool $110 \mathrm{~K}$.

Currently, ETW has two exchangeable model support modules, so-called model carts for full-model support that enable testing at Mach 0.8 with 50 and 85 million in Reynolds number, matching flight conditions of aircraft as large as the Airbus A340 and A380, respectively. One of the model carts is adapted to allow half-model testing. By variation of tunnel stagnation pressure and temperature, flow parameters like Mach number, Reynolds number and dynamic pressure can be varied independently. This enables a distinct separation of compressibility effects, Reynolds number and model deformation effects. Flow separation and its interaction with, for example, the model deformation or shock waves in the flow field, is in general highly Reynolds number dependent. Unsteady interaction may occur which can initiate model vibrations. These physical phenomena often determine the

\section{ESWIRP project: objectives and context}

The project started in October 2009 for a period of 5 years. The project consisted of two major parts:

1. Networking activities between the three partners and implementation of some improvements to the testing infrastructures.

Although the tunnels covered in this project are of complementary nature, the infrastructure activities were joined together, by a common representation of, and approach to, the tunnel performance characteristics. To this end, a generic model of a virtual wind tunnel was developed, enabling operators to assess the effect of the control parameters on the testing conditions. The final aim of all participants was to provide the user community with an improved capacity to test their innovative ideas, and to be able to do this with increased reliability. 
The infrastructure improvements targeted the capability to obtain unsteady test data with high accuracy in the ETW, to improve the capability to simulate aircraft behaviour in ground effect in the LLF, and to establish a reliable closedloop Mach number control in the S1MA wind tunnel.

2. The provision of wind tunnel access to research groups which do not usually have the means to access such large-scale test facilities. These topics also involved public dissemination and information activities.

To provide better access to these three major wind tunnels, mainly research groups from European universities were contacted. The approach taken has included maximum transparency of the process and support of the researchers by the organizations responsible for the tunnels. In addition, when possible, research groups were encouraged to work together, to obtain the full benefit of economies of scale in research projects.

European Strategic Wind tunnels Improved Research Potential Program responded to the targeted approach of the Integrating Activities of the FP7 Capacities Work Program.

\section{Mathematical modeling}

An innovative approach to model the operational behaviour and the time-dependent flow quantities around a wind tunnel circuit was developed, to help designers to make better decisions, before the implementation of novel hardware.

The objective behind this approach was that before making far reaching decisions regarding the implementation of novel hardware or adaptations of the control systems, the tunnel operator should have a virtual model of the wind tunnel circuit at his or her disposal. This model simulates the interaction between control inputs and physical phenomena in the wind tunnels and engenders maximum confidence that the new features will work satisfactorily, and hence justifies the scope of investments and/or ensures safe operation of the facility. The proposed model was universal for all three facilities, to demonstrate the complementary aspects, but to take into account the peculiar properties of each. To achieve this, in addition to a generic numerical model, three extra modules were required to cope with these diversities.

The mathematical model considers the existing tunnel geometry, and was aimed at a realistic representation of the physical phenomena in the flow. The virtual tunnel was divided into a number of single volumes, defined by an entry station and an exit station (axially). The basic thermodynamic behaviour such as: temperature exchanges, pressure losses, mass flow equation (injection or blow-off), are considered at different stations along the circuit. The main drive of the facility (compressor or fan) was approximated as a disk introducing energy through a pressure difference, and the tunnel characteristics, which are essential to the flow behaviour (plenum volume, nozzle, fixed contraction, diffuser, second throat if any, test section, etc.)

As an example, the ONERA-S1MA model features some simplifications: the air exchanges with the atmosphere are not simulated and flow temperature is controlled by the mean of an internal heat exchanger.

The circuit is divided into individual volumes in which the time-dependent equations are resolved.

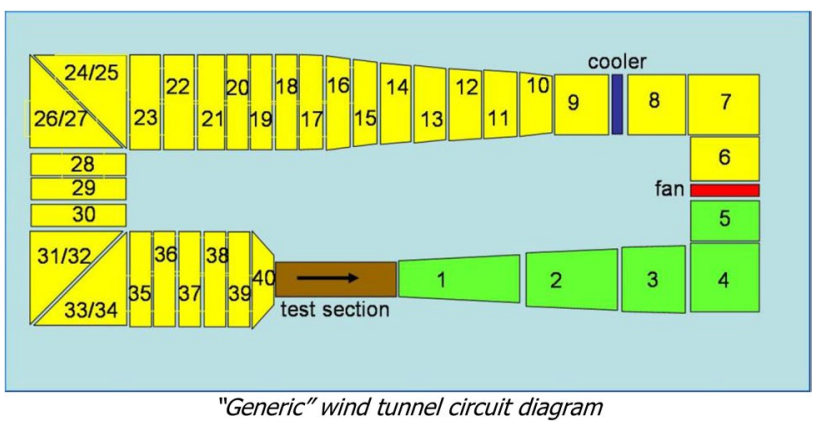

The individual circuit volumes are characterised by their geometry (mean diameter, length and wetted area), their pressure loss coefficient and the thermal exchange coefficient through the walls of the circuit.

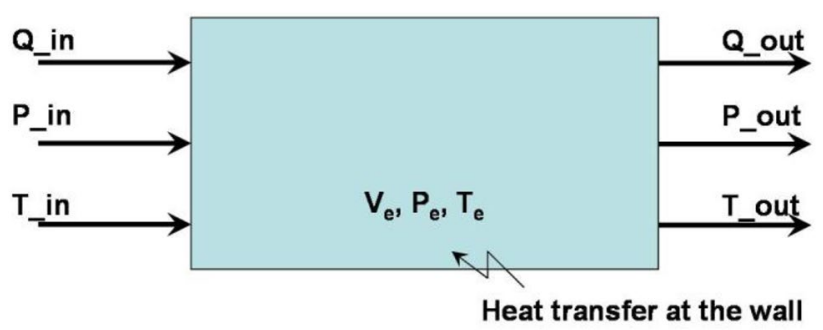

Circuit element module inputs/outputs

The main control parameters of the generic model are the fan rotational speed (RPM) and the cooling power of the heat exchanger.

Following the generic model, three dedicated models were developed, one per facility (S1MA, LLF and ETW). Each model is based on the generic model, but adapted to specific wind tunnel parameters.

The validation was performed as follow:

1. each module has been tested on a mathematical point of view,

2. the qualitative behaviour of each module has been checked, 
3. the results obtained by running the assembled model have been compared with tests provided by each wind tunnel operator.

For example, S1MA experimental data and numerical results are given on the two tables below:

Experimental data

\begin{tabular}{lllllll}
\hline Mach & $P_{\text {atm }}(\mathrm{Pa})$ & $T_{\text {atm }}(\mathrm{K})$ & $\mathrm{Pt}(\mathrm{Pa})$ & $\mathrm{Tt}(\mathrm{K})$ & $\begin{array}{l}Q_{\text {exhaust }} \\
(\mathrm{kg} / \mathrm{s})\end{array}$ & $\begin{array}{l}\text { Fan } \\
\text { speed } \\
(\mathrm{rpm})\end{array}$ \\
\hline 0.80 & 88.182 & 286 & 88.411 & 323 & 876 & 180 \\
0.60 & 88.167 & 295 & 88.350 & 316 & 784 & 150 \\
\hline
\end{tabular}

Numerical results

\begin{tabular}{lllllll}
\hline Mach & $P_{\text {atm }}(\mathrm{Pa})$ & $T_{\text {atm }}(\mathrm{K})$ & $\mathrm{Pt}(\mathrm{Pa})$ & $\mathrm{Tt}(\mathrm{K})$ & $\begin{array}{l}Q_{\text {exhaust }} \\
(\mathrm{kg} / \mathrm{s})\end{array}$ & $\begin{array}{l}\text { Fan } \\
\text { speed } \\
(\mathrm{rpm})\end{array}$ \\
\hline 0.80 & 88.182 & 286 & 88.454 & 327 & 879 & 187 \\
0.60 & 88.167 & 295 & 88.371 & 322 & 782 & 146 \\
\hline
\end{tabular}

From these two tables, we can notice the following errors values:

- unnoticeable differences for the total pressure,

- $2 \%$ for the total temperature,

- less than $1 \%$ for the exhaust flow,

- $3-4 \%$ on the fan rpm.

It can be considered that the model is able to represent S1MA behaviour with an error less than 5\%, which is acceptable for the purpose of such a model.

\section{Infrastructure improvements of the participating facilities}

\subsection{ONERA S1MA improvement}

The proposed upgrade of S1MA within the ESWIRP program was aimed at improving the wind tunnel quality and productivity by implementation of a closed-loop Mach number control system. The work has been to determine the best control strategy via modeling of the flow behaviour, and then to design and implement a control mechanism.

To provide an acceptable test environment, the Mach number fluctuation need to be limited to \pm 0.001 , at least up to Mach 0.9, which is an improvement by a factor of 5 over the previous situation. To achieve this goal, it was necessary to design and implement a flow control device in the wind tunnel circuit.

An air inlet with flaps called EAR inlet ("Entrée d'Air de Régulation"- - additional air inlet for Mach regulation) was studied. With this device, a small mass flow rate is injected, goes through the fans and goes out by the annular exhaust of the wind tunnel located just upstream the contraction.

The purpose of the EAR is to compensate for the variation of the pressure losses coming from the model (as its angle of attack is changed), by injecting a small air mass flow rate just upstream of the fans of the wind tunnel. In fact, the EAR was located on the corner \#1 of the wind tunnel just upstream of the two S1MA contra-rotating fans.

\subsubsection{Main characteristics of the EAR}

The EAR inlet is powered by natural aspiration, because the static pressure inside the wind tunnel circuit while running, is always lower than the outside atmospheric pressure. Its location at corner 1 just upstream the fans, is the most favourable one, because the internal static pressure there is the lowest in all the circuit.

The pressure difference available across the intake is usually between 2000 and $6000 \mathrm{~Pa}$, according to the Mach number and the pressure losses associated with the model mounting in the test section. The maximum mass flow rate of the air intake is estimated by CFD calculation to be $250 \mathrm{~kg} / \mathrm{s}$.

From upstream to downstream, the aerodynamic EAR inlet circuit consists of:

- A rectangular contraction with an inlet protection screen of $4.50 \mathrm{~m} \times 1.60 \mathrm{~m}$ located at "air inlet 1 " of the S1MA wind tunnel circuit.

- A central air box of section $2.50 \times 1.05 \mathrm{~m}$ including two vertical flaps. The angle of the flaps can be continuously changed between $0^{\circ}$ (fully open position) and $75^{\circ}$ (fully closed position).

- A bent feeder pipe entering the tunnel circuit at $45^{\circ}$ is fitted with 4 guide vanes to promote uniform flow into the tunnel.

The motorization of the flaps is mounted above the central air box, and includes an electric motor with a single central screw and two crank-rod mechanisms. The motorization is protected by a shelter which also includes an electrical cabinet. The EAR features a footbridge on each side of the circuit for maintenance.

The mathematical model was used to pre-design the air inlet. For the final design, ONERA CFD tools were used. 


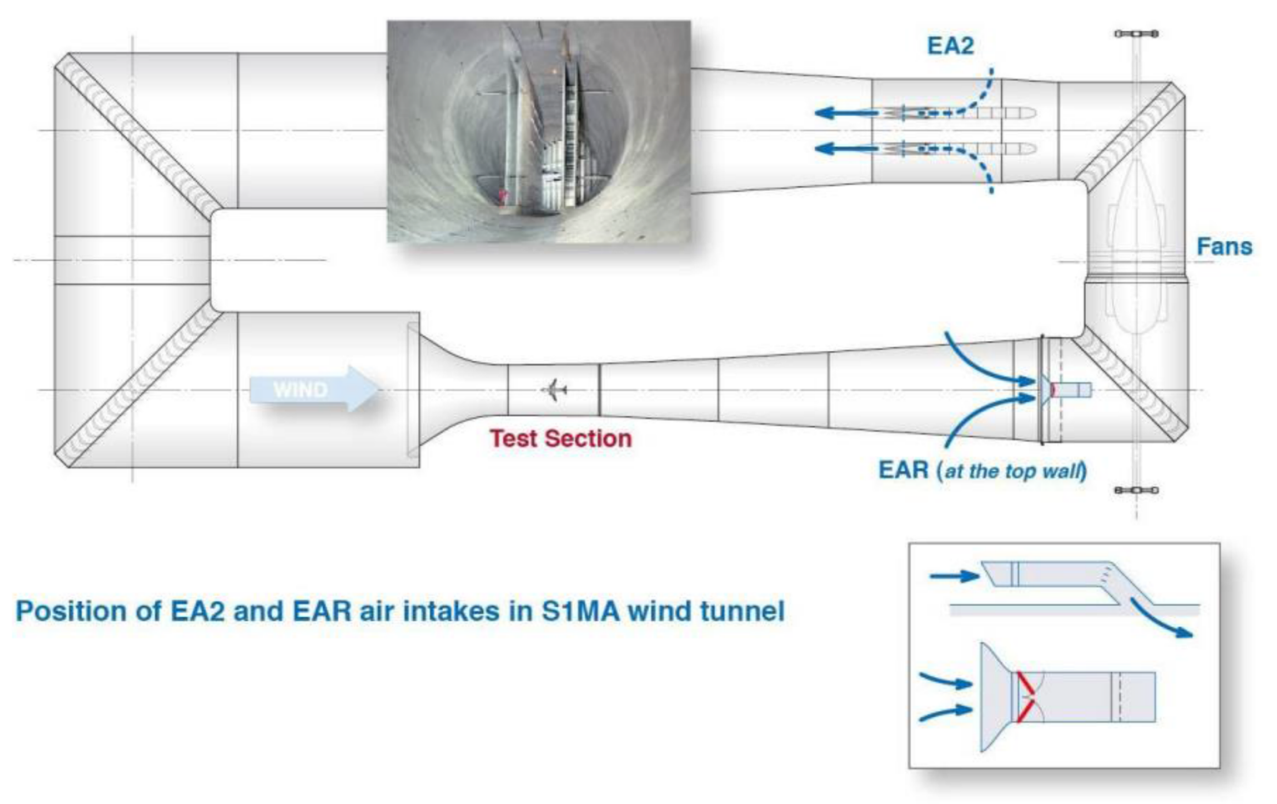

\section{The mounting of the EAR inlet at corner 1 of the S1MA circuit took place during the Summer of 2012.}

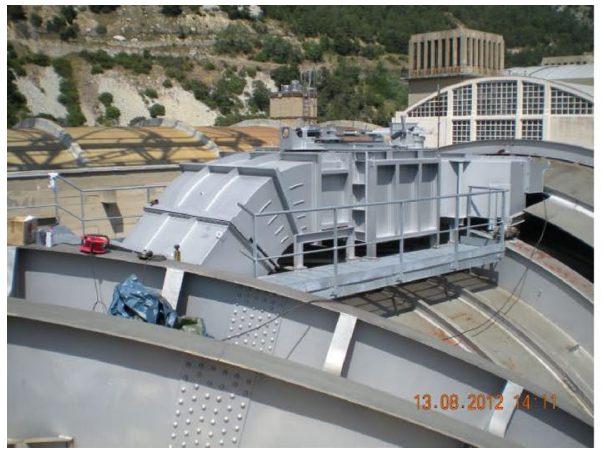

EAR inlet circuit mounted without its shelter.

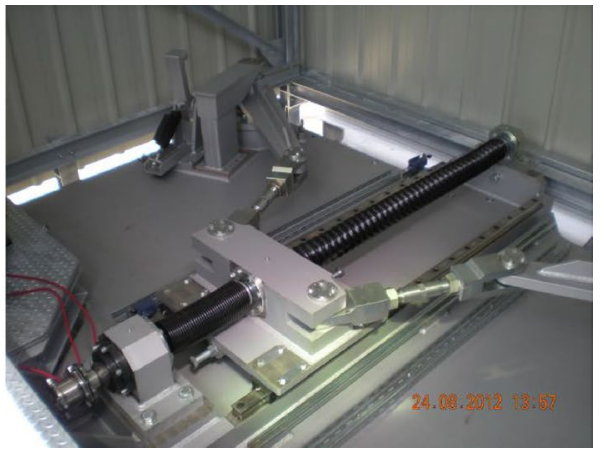

Motorization of the flaps.

\subsubsection{Tests performed to commission the new Mach number regulation system}

Tests were performed in November 2012, using a civil aircraft model at a scale of $1 / 26$, in the S1MA test section no. 2-45 $\mathrm{m}^{2}$ cross-section, to commission the new Mach number regulation system using the EAR air inlet.

Measurements were performed on the one hand with the classical Mach number regulation using the main air inlet, and on the other hand with the new regulation system in operation. This new system was specially developed to take advantage of the new additional air inlet. Based on the previous experience with the large air intake, the idea was to use the fan RPM controller to compensate large pressure losses with some time delay, in association with a smaller air intake device, which can generate limited but fast pressure variations, in phase opposition to those of the model during a pitch sweep. 
The efficiency of operation and the effect on the model test conditions of the EAR air inlet, were evaluated in these tests.

Mach number drifts found with the new regulation system are presented on the figures below:
Indeed, nearly no drifts were observed for all Mach numbers, even with the model at negative angle of attack. The goal of this work had been achieved, and all future customers of the S1MA since 2013 have benefited from this improved Mach number control.

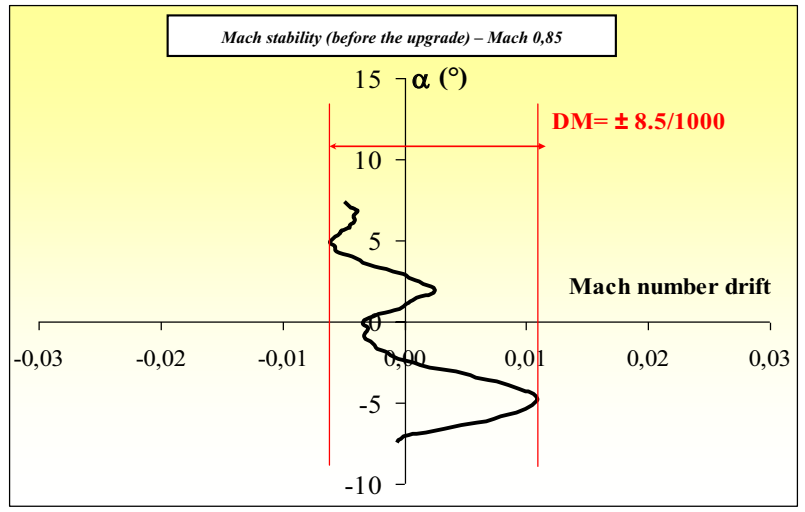

Mach number drift during a pitch sweep - Original Configuration, before the upgrade - Mach 0.85.

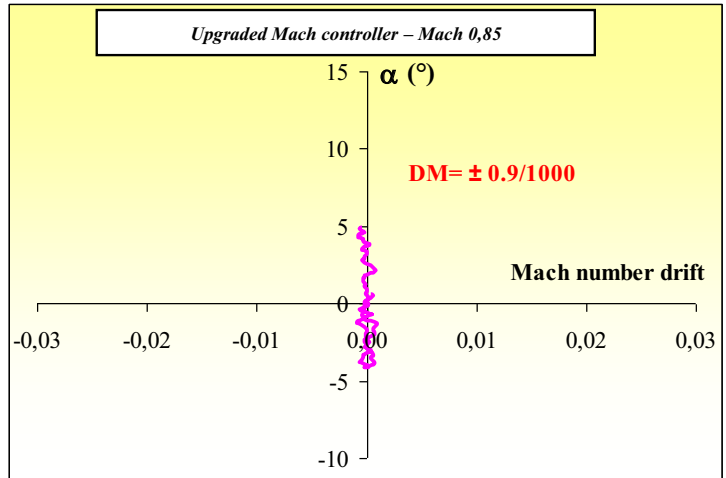

Mach number drift during pitch sweep - Final regulation system in operation 2014 - Mach 0.85 .

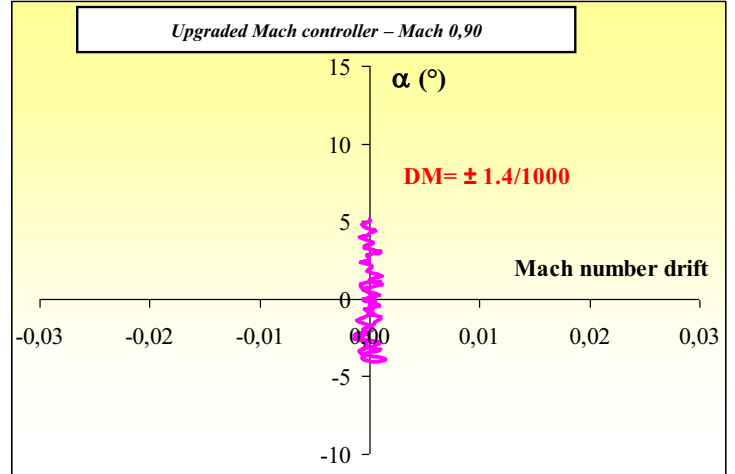

Mach number drift during pitch sweep - Final regulation system in operation 2014 - Mach 0.90.

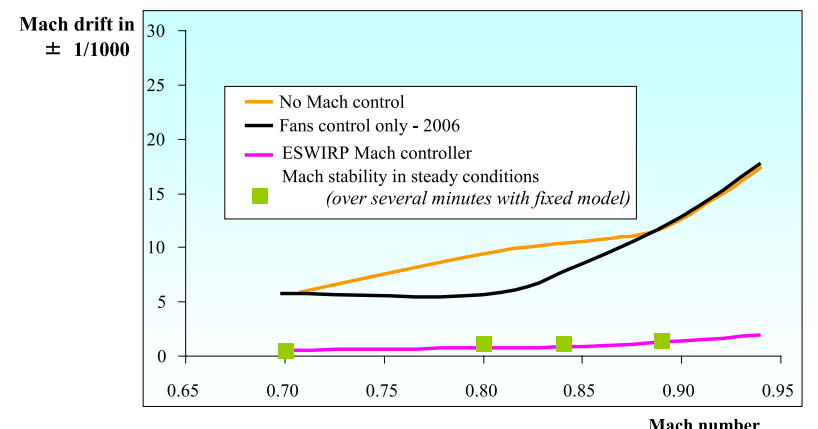

Synthesis of Mach number drift during a pitch sweep - Curves in orange and black illustrate the initial Mach number drift with no ESWIRP Mach controller. Pink curve shows the improvement due to the ESWIRP
Mach controller.

The figures above illustrate the impressive improvements achieved with the new S1MA Mach number controller.

\subsection{DNW-LLF upgrade}

The DNW-LLF wind tunnel has specifically been designed for testing take-off and landing conditions of aircraft. For this purpose, an important simulation technique is the socalled ground simulation. The runway is simulated by a moving belt system, with a maximum belt speed of about $40 \mathrm{~m} / \mathrm{s}$, before the upgrade. Furthermore, the system comprised of a boundary layer removal system that removed and re-injected the floor boundary layer air into the tunnel circuit.

The upgrade of DNW-LLF was focused on a major improvement of the moving belt [1]. The upgrade should enable an improved simulation of the relative motion between a powered aircraft model and the simulated runway.

The required improvements relate to: 
- flatness of the belt under expected future heavy upward and downward aerodynamic loads,

- prevention of hot areas on the belt due to friction with the belt bed,

- wear of the belt and therefore a longer lifetime of the belt,

- tracking of the belt under asymmetrical aerodynamic loads.

The realization of these improvements was intended to give a better simulation of the take-off and landing of aircraft, especially for future new engine concepts. In addition, the reliability of the system was set to improve, which would consequently increase the test productivity that can be offered to the aeronautic community in the future.

The upgrade concentrated on improvements regarding:

- control concept of the belt,

- belt bed,

- belt suction/blowing system,

- cooling system.

For each item, a feasibility study was performed detailing potential benefits, and making cost trade-offs. The studies indicated that the required ground simulation improvements could not be realised with the existing system (using a multilayered fabric belt). The potential benefits could only be realised by implementing a metal belt system.

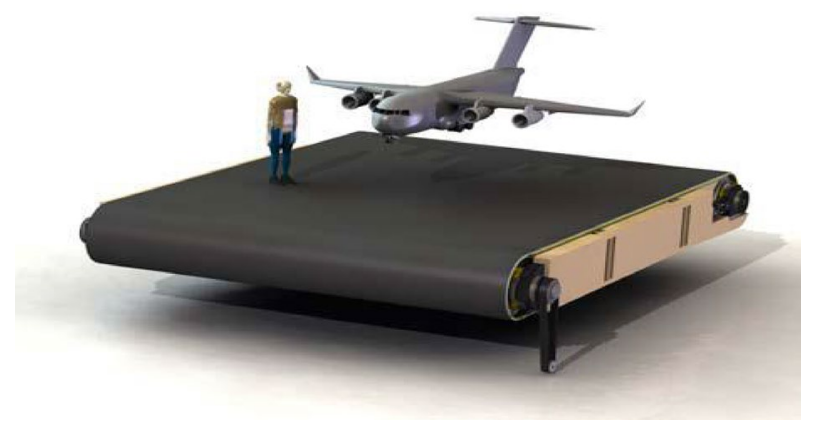

The metal belt MBGP system proposed for LLF.

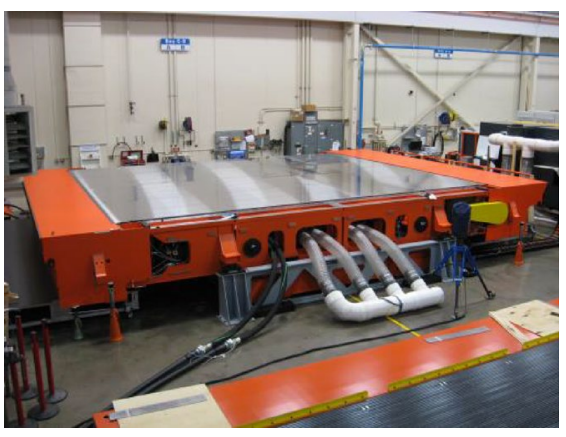

DNW moving belt during the

factory acceptance test
The new MBGP specifications were:

- Belt size $7.92 \mathrm{~m} \times 6 \mathrm{~m}$.

- Maximum belt speed Mach $0.25(80 \mathrm{~m} / \mathrm{s}$ - double the previous speed).

- Long lifetime.

- The belt remains flat under the influence of aerodynamic forces introduced by models mounted above the belt.

- The flatness of the belt needs to be measured, to control an automated reaction by the air suction/pressure system.

- Boundary layer removal using an existing ground plane (200 mm scoop).

The system corresponding to the above requirements was manufactured by an external company, and delivered at LLF at the beginning of 2013. After a site-acceptance test, a dedicated test in the DNW-LLF was performed to optimize the belt settings. These settings were optimized to obtain a homogeneous pressure distribution above the new moving belt. After optimization, a static pressure coefficient $\left|C_{\mathrm{p}}\right|<$ 0.003 above the belt existed up to the nose.
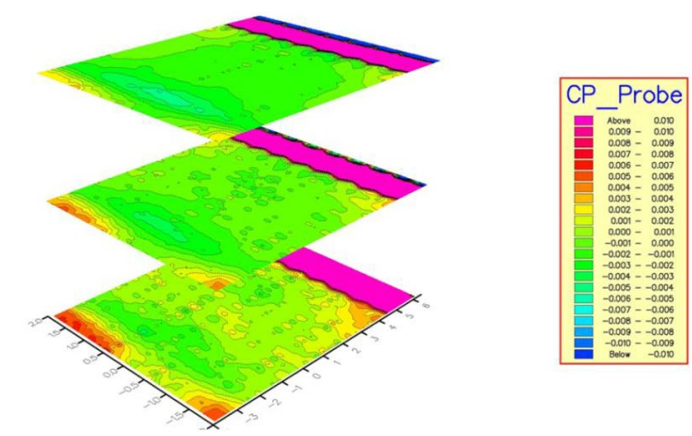

Static pressure distributions of 10 meter $x 4$ meter size at $500 \mathrm{~mm}$ above the belt for three different velocities: $v=40,60$ and $70 \mathrm{~m} / \mathrm{sec}$.

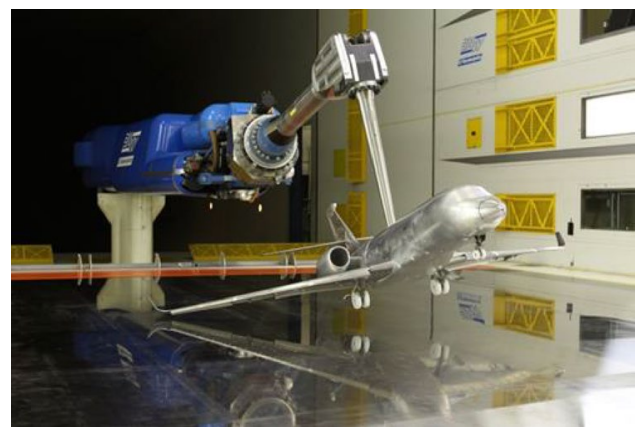

DNW moving belt in operation 
The new DNW-LLF belt system has been operational since March 2013. The new belt system is a world-class ground simulation technique, which meets all DNW requirements. The first industrial test was performed in April 2013, and since then various industrial tests have been successfully carried out. Feedback of these customers confirmed that the realization of the improvements have increased the fidelity of the in ground effect simulation capabilities of the DNW-LLF.

\subsection{ETW upgrades}

The design and development of future eco-efficient high performance transport aircraft implies the need to operate closer to the physical flight boundaries compared with today's designs. As the flow fields in these flight regions are characterised by complex three-dimensional and potentially unsteady flow behaviour, the industry needs accurate and reliable wind tunnel test data from such regions. These requirements can only be satisfied by providing sophisticated state-of-the-art instrumentation, ideally of the non-intrusive type, validated over the cryogenic, pressurized operating range of the ETW.

The ETW improvements focused on the provision and verification of tools and techniques to improve/enhance the test capabilities of ETW and, thereby, extending the portfolio of capabilities available to their customers.

A set of 12 individual smaller projects were defined, which referred to specific needs identified at ETW, taking into account priorities, feasibility and budget for a successful realization of the projects in the ESWIRP timeframe. The first 11 projects refer to the upgrade and enhancement of unsteady test capabilities, the last project no. 12 was focussed on an overall productivity increase and saving of operational costs. A short description of each project follows:

\subsubsection{Enhancement of unsteady/aeroelastic test capability and operational productivity}

\subsubsection{Feasibility study for an extension of the operating} range of the half-model balance Using a half-model for aeroelastic testing is typically to assess the unsteady behaviour of aerodynamic forces and moments, pressures and the corresponding model shape. While the base frequency is mostly below $100 \mathrm{~Hz}$, first and second harmonics, often strongly amplified, appear at frequencies of a few hundred Hertz. Hence, for a proper analysis and assessment of aeroelastic characteristics, the Eigenfrequency of the model/balance support system must be acceptably higher.

While determining this status experimentally, the half-model balance was also meshed, and subsequently
Eigenfrequencies were calculated using a finite element (FEM) code. Meanwhile, the mechanical structure itself was equipped with a series of accelerometers, for in situ measurements during testing.

It was found, that the calculated Eigenfrequency $(230 \mathrm{~Hz})$ was lower than the measured one $(300 \mathrm{~Hz})$. Unfortunately, no feasible solution for a reinforcement of the balance frame structure could be worked out to change the Eigenfrequencies. Alas, the modification of the structure of the complete model cart was not considered as an acceptable option within the frame of ESWIRP.

5.3.1.2 Increasing the speed of the ETW dynamic model deformation system up to $1 \mathrm{kHz}$ (D-SPT) With respect to the tracking of the unsteady deformations of wings or high-lift model components, the recording capacity of the existing SPT system was completely inadequate. Hence, a new stereo system based on more modern cameras (with increased frame rates but acceptable resolution) was required, combined with associated optical components like objectives, cables, connectors, light sources. Following the procurement and software adaptations provided by the supplier, basic system trials were performed in the ETW lab.

This system tests at cryogenic temperatures, demonstrated a reliable operation, with a frame rates up to $386 \mathrm{~Hz}$, with full resolution images and viewing field. At lower resolution and reduced viewing field, sampling rates up to $1 \mathrm{kHz}$ were achievable. The new system was installed in ETW, and used in the TNA test entry, for monitoring the dynamic behaviour of the HTP of the CRM full-model.
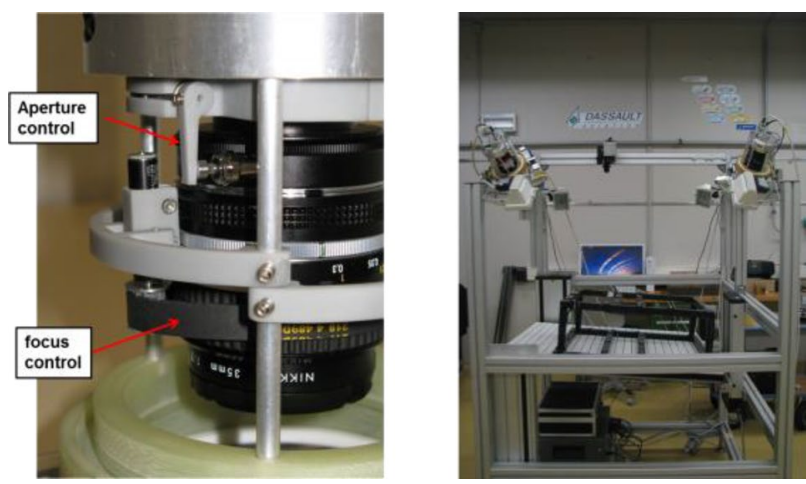

Calibration set-up for Stereo Camera system

\subsubsection{Transition detection by conditional sampling} (CS-TSP) The boundary layer transition detection using temperature sensitive paint (TSP) was successfully developed in cooperation with DLR, more than a decade ago. The technique has also been enhanced and automated for cryogenic operation, so that it may be considered as a mature tech- 
nique. Regarding unsteady flow measurements, the implementation of a phase sampling technique looked essential and feasible. All TSP hardware including the paint, the processing and post-processing software, as well as the operational knowledge was owned by DLR. Hence, their special team had to be in attendance, each time TSP was required in ETW. This situation in the present period of increasing demands on laminar flow investigations at near flight Reynolds numbers, has caused an inacceptable reduction in the operational flexibility of ETW.

The project CS-TSP involved the implementation of conditional sampling as mentioned above, and the transfer of knowledge and software to ETW, including staff training, thus giving a high level of independence to ETW for TSP measurements. Hardware was procured including cameras, objectives, heated boxes and PCs for image control and data processing. Nowadays, all test conduction critical operations of the TSP system can now be performed by ETW staff, when required.

\subsubsection{Upgrading the standard CRYO\#PIV to time-resolved} CRYO\#PIV (TR-PIV) The general application of the particle image velocimetry (PIV) for non-intrusive flow field measurements in wind tunnels is considered mature for operations at and near ambient test conditions. To respect the requirements of the approved TNA-entry in ETW, the tried and tested PIV system had to be upgraded to provide unsteady PIV measurements of wake flows, at cryogenic, pressurized conditions over the full range of Mach numbers. Applying the technique to the associated full-model revealed the need for: (a) the design and manufacture of a new smaller, temperature controlled, housing for the optical module, to be placed below the test section floor; (b) the design and manufacture of a similar large box for a suitable high-speed camera; and (c) the implementation of a complex new light path for the laser beam.

All these challenging tasks were successfully carried out on time for the TNA-entry in ETW. Hence, the time-resolved Cryo\#PIV has fulfilled the mandatory prerequisite for the relevant project objective.

\subsubsection{Increasing the capacity of the unsteady data acqui-} sition system (UDAS) The former existing unsteady data acquisition system at ETW, limited the number of input channels to 64 .

Based on experience with recent test campaigns, this number was not adequate to fulfil client's needs, regarding the number of signals to be acquired in a typical aeroelastic test. Furthermore, the capacities of the electronic filtering units were also insufficient, and there was no individual excitation capability for individual channels. An additional 128 channel system was, therefore, designed according to ETW's specification, tested for acceptance and finally integrated into the measurement pool. ETW is now better equipped to tackle future aeroelastic tests.

\subsubsection{Building a new half-model balance for redundancy} and faster exchange (new HMB) The existing ETW balance for half-model testing has been in operation for almost two decades. Installed in the ceiling of a model cart, it could only be accessed after having removed the test section ceiling, a time consuming operation.

For half-model testing, ETW had no other ceiling balance that was available for substitution in case of a defect or failure, requiring a long period out of service. A careful critical analysis of operations and experiences gathered over more than a decade produced a new specification containing a set of selected modifications and improvements to the existing balance. In this context, the major item identified was the provision of a capability to install the new balance without removal of the test section ceiling (a part of a model cart), for time saving reasons. Regarding the load capacities, sensitivities and accuracy, no modifications were made. The new balance was commissioned successfully and put into operation. The old ceiling balance is now stored as a backup.

\subsubsection{Building a second anti-vibration system for redun-} dancy and time saving (new AVS) European transonic wind tunnel has an anti-vibration system named AVS for suppressing model vibrations, due to aerodynamic excitation or aeroelastic instabilities. The system allows testing up to higher angles of attack, than would otherwise be safe to do. One piezo-actuator is located between the balance and the sting, and linear motors are embedded in stub-stings to counteract pitch and heave oscillations.

Initially, only a single AVS was available, and this sensitive piece of equipment had to be removed and installed in different stub-stings, depending on the individual test requirements. This posed a significant risk to the availability of AVS test support for a given test. To overcome this bottleneck and mitigate the risk, the initial system was adapted and a second (copy) was implemented and commissioned at ETW. Now, ETW has two exchangeable AVS systems in operation, to better meet the test schedule of clients.

\subsubsection{Extending and upgrading of the fibre-optic net-} work The high operating costs of cryogenic wind tunnels demand a high level of reliability and quality of data transfer for all systems active in a test. This requirement is of major importance in ETW, where the tunnel circuit is about $70 \mathrm{~m}$ away from the main tunnel control-room, and a series of cables and optic-fibres are run through cryogenic and ambient environments. Having started cryogenic tunnel operations in the 1990s using classical copper cables, the capabilities of modern measurement and control systems cannot be adequately supported by this type of cable. The developed 
and realised concept is based on 50/125 m glass-fibres of OM3 quality, leading to a reliable data connection with high bandwidth network, to operate and link measurement and data storage systems.

\subsubsection{Upgrading of the data acquisition unit (DAU) Since} the early 1990s, ETW has operated about 160 conditioning units (CUs) developed by the Netherlands Aerospace Centre NLR, for the conditioning and digitalisation of analogue signals. Their capabilities were generally appropriate, but some electronic components had became obsolete, and they did not comply to current communication standards. Consequently, the DAU capabilities were enhanced, in particular focusing on the replacement of the data bus by a modern Ethernet bus, and the integration of a "True RMS" function, enabling a TCP/IP communication and online RMS evaluations.

\subsubsection{Introducing of time synchronization for multi- ple measurement systems using a central clock generator} (CS) European transonic wind tunnel follows a modular measurement system approach for its data acquisition. For unsteady measurements or optical measurement techniques, data was recorded individually and asychronously, e.g., for dynamic pressure transducers, PIV, and hot-wires. However, comprehensive unsteady measurements require a clock synchronization system, which offers high precision on the one hand, and individual adaptability on the other hand. The adaptability is necessary to cope with the wide range of potential subsystems to be synchronised.

The implemented system is able to generate synchronised pulses between $0.01 \mathrm{~Hz}$ and $10 \mathrm{MHz}$ representing the range of data acquisition rates available at ETW, and covering the data acquisition needs of unsteady testing. The new clock synchronization also allowed the generation of other precise pre-programmed trigger sequences, and the time-stamping for triggering external devices, as required. Thus, unsteady measurement data from different sources can now be synchronised and assessed in relation to each other, which is essential, e.g., to investigate aeroelastic phenomena.

\subsubsection{Enhancing unsteady data storage capacity} (U-DAS) Modern unsteady testing requires enhanced data storage capacity, because there are more measurements to be made. Currently, the acquisition of for example, dynamic model deformation data and time/phase resolved TSP and PIV data is requiring modular data acquisition and analysis systems for the gathering and storing of significant quantities of data. Appropriate data storage is the key to providing reliable and rapid "turnaround", i.e., quick saving and access of data for allowing ad hoc detection of measurement errors, discrepancies, failures or loss of data. Furthermore, the operating system has to ensure data storage reliabil- ity using automatic health monitoring, combined with the capability to support a wide range of individual test setups. Each setup has different modular measuring techniques and associated components. Previously, data were distributed over individual disk arrangement of each test system, and hence manual collection was required, to make combined data assessments. Thanks to the U-DAS and the fibre-optic network system, data is now stored centrally for analysis.

A scalable gigabit-connected network attached storage (NAS) solution was installed at ETW. This NAS allows quick data-reading and writing access, as well as inherent redundancy to satisfy high access demands associated with large data quantities. This means that now the data acquisition may continue writing a stream of data, while simultaneously preliminary data analysis can be performed checking the consistency and quality of the acquired data. Furthermore, intelligent continuously running cloning/backup algorithms significantly reduce the risk of losing valuable test data.

\subsubsection{Developing and prototyping an RC-slot sys-} tem European transonic wind tunnel test section walls may be configured either solid or slotted to minimize wall interferences. Testing full-span models requires longitudinal slots in the floor and ceiling of the test section. Half-span models are attached to the modular model cart resembling the test section ceiling. Consequently, for this type of testing, all walls may be solid or, both the side walls slotted with the top and bottom walls solid. Previously, the wall configuration was achieved using prefabricated heavy inserts, manually bolted to the wind tunnel structure. Consequently, the required configuration changes require several days of access to the tunnel, under ambient conditions. A new concept has been developed to minimize this time consuming and costly procedure. A firm requirement of the new design was to have negligible interference with the flow around the test object, to avoid a complete recalibration of the wind tunnel over its full operating range.

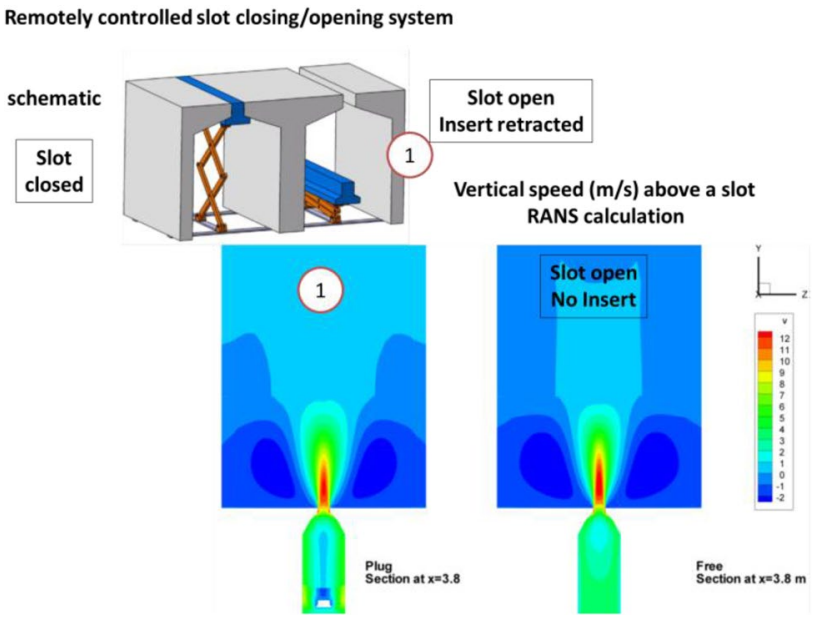


European Strategic Wind tunnels Improved Research Potential Program allowed a prototype to be produced, which was successfully demonstrated under ambient and cryogenic conditions, in a variable temperature chamber. This concept was further refined in subsequent prototype tests in ETW during 2015. The electric motors turned out to jeopardize operational reliability for long-term cryogenic testing. Thus, the system was reconfigured for manual operation using a cordless electric screwdriver. Although personal access at ambient conditions is still required, the slot conversion openclose or vice versa can now be completed by a single person in $2 \mathrm{~h}$ only. Formerly, 4 people had to work for 3 days for completing this change of wall configuration. The modified system has been successfully implemented in the meantime.

\section{Trans-national access (TNA): information campaign and call for proposals}

A series of three workshops was organized, to maximize the opportunity for research groups, to propose and discuss potential projects with the three ESWIRP consortium members. Invitations for the workshops were sent to experts at aeronautical university faculties and industry from the European Union and its Associated Members. Each of these three ESWIRP workshops took place near one of the participating wind tunnels, and lasted for 2 days.

The ESWIRP website contained all relevant information for the workshops (i.e., topics, deadlines, workshop announcements, etc.) including an expert system, which enabled potential users of the facilities to match their needs with the Consortium's capabilities.

At all the workshops, both the ESWIRP wind tunnel experts and independent experts (who later formed the "ESWIRP review team") were present to advice and support the project teams. Shortly after each workshop, a complete set of documentation was published on the TNA webpage of the ESWIRP website "http://www.eswirp.eu". The Consortium organized three workshops with a progressive approach.

First workshop-Cologne-ETW facility-November 2010

- To collect the first panel of ideas, and identify various test objectives.

Second workshop-Modane/Bardonecchia—S1MA facility-March 2011

- To consolidate the ideas for the projects by forming potential consortia.
Third workshop—Zwolle/Marknesse_-LLF facility_October 2011

- To help researcher groups to prepare answers to the call for proposal.

- To implement consolidation of the interested partners.

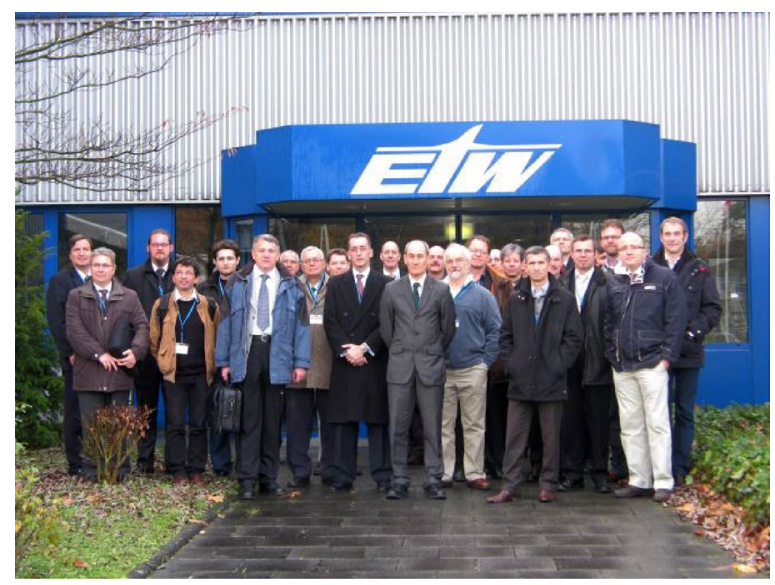

Thirty participants including the ESWIRP team, attended the first workshop in November 2010 at ETW.

During these three workshops, tours of each of the participating wind tunnels were organized. All participants had the opportunity to discuss measurement techniques and wind tunnel capabilities with local experts. This clearly contributed to a better understanding between wind tunnel operator and user.

The workshops provided valuable opportunities for the participants to gather sufficient information to be able to answer the TNA Call for Test Proposals. During the meetings, it was also possible for participants to ask the Consortium about administrative rules for this TNA.

During the three workshops, the Consortium reached out to more than 80 people, coming from 12 countries. After the third Workshop, the Consortium issued the Call for Test Proposals.

At the end of the advertising process, six research groups proposed projects for this TNA opportunity. From these, four projects were selected.

To evaluate the submitted proposals, the Consortium appointed a review team consisting of three experts from academia, research and the industrial communities, with experience in aeronautics and wind tunnel test and measurement techniques.

The Consortium, in accordance with the review team, established a selection criterion list, which was 
published-according to the European guidelines-before the selection, to assure the competition was fair.

\begin{tabular}{lc}
\hline Criteria for selection & Weight (\%) \\
\hline $\begin{array}{l}\text { Technical intrinsic value and interest } \\
\text { Innovative potential and scientific value for the com- } \\
\text { munity }\end{array}$ & 50 \\
Potential added value to the understanding of flow \\
physics \\
$\begin{array}{l}\text { Quality (and cohesion) of proposing team(s) } \\
\text { Number of users }\end{array}$ \\
$\begin{array}{l}\text { Number of nationalities } \\
\text { European representativity }\end{array}$ \\
$\begin{array}{l}\text { Importance and relevance of the upgrades to the } \\
\text { ESWIRP program }\end{array}$ \\
Alinement with facility capabilities \\
Total
\end{tabular}

The four selected projects are described as follows.

\subsection{Project for the S1MA wind tunnel}

\subsubsection{Investigation of the small scale statistics of turbulence in the Modane S1MA wind tunnel}

The selected proposal for S1MA was aimed at a detailed experimental investigation of the statistical properties of turbulent flows at large Reynolds numbers. Though computational fluid dynamics has made impressive progress in the last few decades, so have the requirements in terms of modeling accuracy. Effects of turbulence are among the most difficult to simulate and predict, and they still require fundamental investigations and experiments to be better understood. As recently discussed during a dedicated session of the French Academy of Science, dedicated to advances in fluid mechanics research, one crucial and wellidentified challenge, concerns the comprehension of energy cascade and dissipative mechanisms of turbulence, which have important consequences in practical situations found in aerodynamics, combustion, pollutant dispersion, etc.

The primary goal was to take advantage of the unequalled large-scale dimensions of the ONERA S1MA wind tunnel facility in Modane, to make available to the broad scientific community experimental turbulence data with unprecedented resolution (both spatial and temporal) and accuracy (in terms of statistical convergence quality).

The experiment focused on the study of grid generated turbulence. A large-scale grid (10 $\mathrm{m}$ in diameter, with a mesh size of $0.625 \mathrm{~m}$ ) was used as a turbulence generator, since it is known to produce canonical homogeneous and isotropic turbulence. This is an academic flow known to produce almost perfectly homogeneous and isotropic turbulence (HIT), which remains a unique playground to investigate fundamental properties of turbulent flows. The characteristics of turbulence were measured downstream by different instruments mounted on a mobile cart in the test section, from $X \sim 0$ to $X \sim 15 \mathrm{~m}$. Measurements were performed during some $15 \mathrm{~h}$ of testing, at six $X$ positions of the mobile cart, and for velocities in the test section ranging from 20 to $45 \mathrm{~m} / \mathrm{s}$.

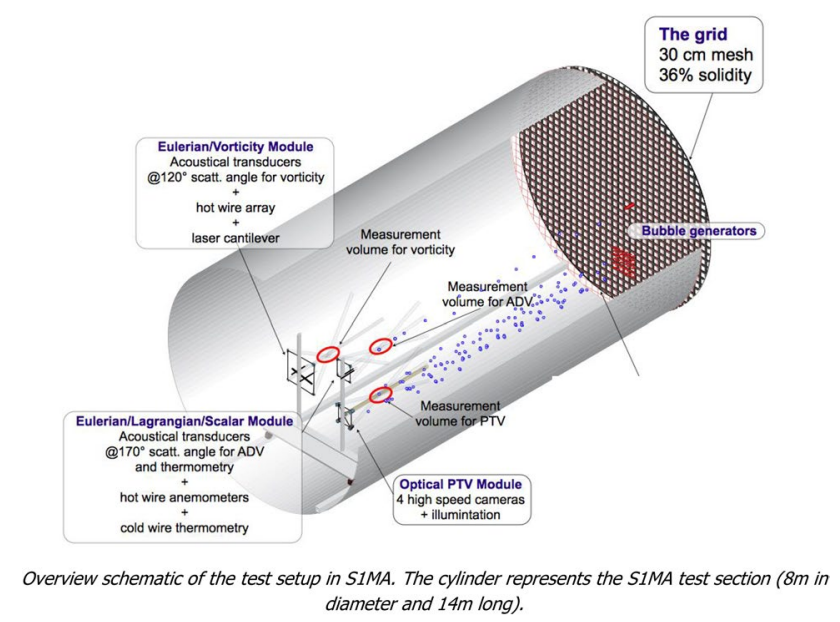

The objective was to produce a database as complete as possible, in terms of characterization of the turbulence, which will help the research community to get a better insight into longstanding mysteries, which still limit the capacity to understand and accurately model turbulent flows.

These include, among other topics, turbulence intermittency, mixing and dispersion properties, and the link between Eulerian and Lagrangian descriptions of turbulence. For this purpose, several measurements were made:

- Hot-wire anemometry.

- Laser cantilever anemometry.

- Lagrangian particle tracking.

- Vortical acoustic scattering.

- Micro-pitot tubes.

To achieve this ambitious project, a large international consortium of 22 scientists was formed with complementary expertise. This allowed a large spectrum of measurements to be selected, in terms of different techniques, high resolution instrumentation, and signal.

The laboratories and institutes that were involved are as follows:

- Laboratory LEGI-Laboratoire des Ecoulements Géophysiques et Industriels (Grenoble, FR).

- Institut de recherche en sciences et technologies pour l'environnement et l'agriculture-IRSTEA (Rennes, FR).

- Neel Institute (Grenoble, FR). 
- LEGI (Grenoble, FR).

- ENS-Lyon, FR.

- Laboratory PPRIME (Poitiers, FR).

- Laboratory "COmplexe de Recherche Interprofessionnel en Aéro-thermochimie" - CORIA (Rouen, FR).

- Academy of Science of the Czech Republic, CZ.

- University of Oldenburg, DE.

- Max Planck Institute (Gottingen, DE).

- Royal Institute of Technology—KTH (Stockholm, SE).

From a scientific point of view, the ESWIRP TNA team has stated that the test campaign was successful. The first analysis has shown indeed that the smallest scales of the flow were well-resolved. This was the main challenge of the test. The different diagnoses are consistent within each other, and with different levels and ranges of noise. The combination of the data recorded with the numerous instruments used, has improved the overall quality of the measurements.

More details about this experiment can be found in the Ref. [2].

\subsection{Project\#1 for the LLF wind tunnel: investigation of the APIAN propeller in non-uniform flow (APIAN-INF) in the DNW-LLF}

Because of their high propulsive efficiency compared to turbofans, propellers are still considered as an interesting option, for the propulsion system of future generations of passenger transport aircraft. A large rotor diameter(s) combined with interior noise constraints has driven possible propeller powered aircraft lay-outs towards a rear fuselage mounted pusher propeller configuration. In such a setup, the propeller blades operate in the wake of the upstream engine pylon, leading to non-uniform inflow on the propeller disk. Hence, unsteady blade loads exist, and there is an associated increase in propeller noise emissions. Literature has shown that pylon blowing can mitigate this noise penalty due to the pylon wake interaction, by re-energizing the pylon wake deficit. This project aimed at experimental and numerical investigations of the aerodynamic and aero-acoustic response of an isolated propeller, subjected to a non-uniform flow field caused by an upstream pylon model. For this purpose, the existing and well-investigated propeller model from the European APIAN project was reused in one of the selected TNA entries into the DNW-LLF.

The primary goal was to acquire experimental aeroacoustic and aerodynamic data of high quality, and make these data available to the scientific community. This goal could be best achieved by taking advantage of the large-scale dimensions of the German-Dutch large low-speed facility (DNW-LLF) wind tunnel in the Netherlands. In particular, the large open-jet test section of the DNW-LLF with acoustic absorbing treatment on the tunnel was most suitable for acoustic far-field measurements.

The first objective of this experiment focused on the study of aero-acoustic measurements of far-field data, with different measurement techniques. For the measurement of unbiased narrow band data, a large number of inflow microphones were traversed over a wide range of $10 \mathrm{~m}$ in the stream-wise direction, relative to the propeller model. With a fixed microphone arrays outside of the open jet, the directivity of the propeller noise was measured over a wide directivity range at a distance of up to $20 \mathrm{~m}$ from the source. By means of three phased microphone arrays, the distribution of the noise sources was localized from different observation positions outside of the open jet.

Acoustic measurements with the propeller model were performed during some $24 \mathrm{~h}$ of testing. Several microphone array positions were used, upstream and downstream of the propeller model, and for a range of velocities between 40 and $70 \mathrm{~m} / \mathrm{s}$, and also over an angle of attack range between $\pm 6^{\circ}$.

The second objective of this experiment focused on the study of the aerodynamic flow around a propeller, using three components PIV measurements. These measurements were performed during some $24 \mathrm{~h}$ of testing, with several positions of the measurement plane upstream and downstream of the propeller model at a constant velocity of $60 \mathrm{~m} / \mathrm{s}$, and also over an angle of attack range between $\pm 6^{\circ}$.

For both the acoustic and aerodynamic measurements, three main configurations were investigated:

- Isolated propeller.

- Propeller with pylon installed upstream of the propeller, with several pylon blowing rates.

- Propeller without pylon and installed swirl recovery vanes (SRV).

The third objective of the experiment focuses on the calibration of the inflow and out-of-flow measurements, by means of two artificial acoustic calibration noise sources.

- Plasma noise source based on spark technology (provided and operated by ONERA).

- Calibration noise source based on loudspeaker technology (provided and operated by airbus).

After the removal of the propeller model from the test section, these sources were placed at the former location of the propeller. Acoustic calibration measurements were performed during some $24 \mathrm{~h}$ of testing, at several positions of the sources and different signal types. The sources were operated over a range of airspeeds between 40 and $80 \mathrm{~m} / \mathrm{s}$.

For this calibration, several measurement techniques were used: 
- Inflow far-field microphone technique.

- Out-of-flow microphone technique.

- Phased microphone array techniques.

- Plasma spark calibration noise source (by ONERA).

- Loudspeaker calibration noise source (by airbus).

- Rotor performance measurements.

- Rotating shaft balance (RSB) technique.

- Torque-meter.

- Blade pressure sensors (27 Kulites).

- RPM signals.

- Flow measurements.

- Standard wind tunnel parameters.

- Model position.

- Three components PIV technique.

- To carry out this project, an international consortium of about 20 scientists was selected, with complementary expertise spanning a large spectrum of measurement techniques, high resolution instrumentation, and signal processing. Technical University of Delft (The Netherlands).

- Research Institute INCAS (Romania).

- Research Institute TsAGI (Russia).

- University of Cambridge (United Kingdom).

- Technical University of Braunschweig (Germany).

- Research Institute DLR Braunschweig (Germany).

- Research Institute ONERA (France).

- Airbus Industries (France).

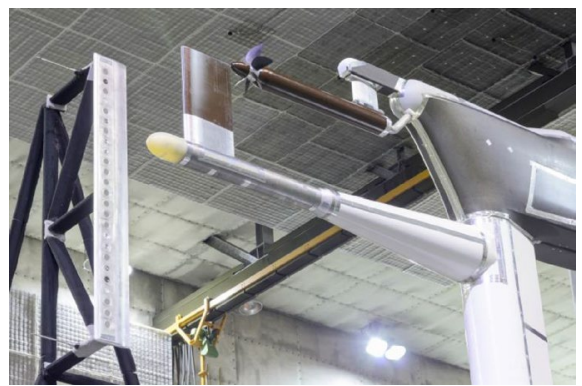

APIAN-INF propeller model with installed pylon.

\subsection{Project\#2 for the LLF wind tunnel: new Mexico wind turbine investigations}

The wind energy community is still demanding high-quality data on wind turbines to validate CFD simulations and design codes. This holds true for performance data, flow field information and certification load cases. In 2006, such a data set was gathered during a wind tunnel test campaign at DNW-LLF financed by the EU, and the investigated configuration was called Mexico. This data set has been used extensively worldwide, and is part of Energy Technology Network (IEA) Wind Task 29 Mexnext (http://www.mexne xt.org). During the last decade, the technology involved in wind turbine design and manufacturing has evolved greatly, giving raise to a need for more detailed wind turbine data. Amongst other topics, noise has become an important aspect of wind turbine design. Since it is hard to gather such data on a full-scale rotor in normal operation, the controlled test environment in a wind tunnel is needed. This is the topic of the second TNA test in the DNW-LLF.

The primary goal of the project is to take advantage of the availability of an existing wind turbine model (Mexico), in combination with the large-scale dimensions of the German-Dutch large low-speed facility (DNW-LLF) wind tunnel facility in the Netherlands. Hence, it is possible to gather experimental aero-acoustic and aerodynamic data of high quality, and make this test setup available to the

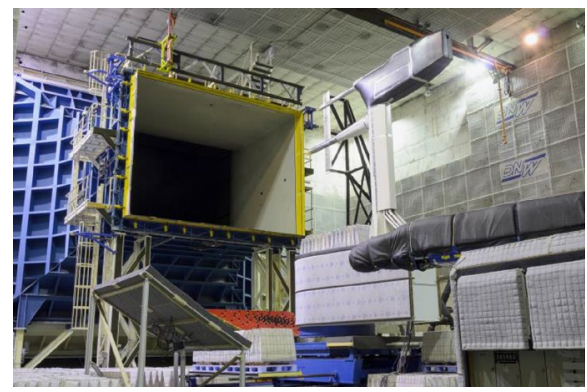

Acoustic calibration setup with installed loudspeaker noise source (provided and operated by Airbus).

The ESWIRP TNA team reported the test campaign was successful. The amount of acquired data was much larger than expected. For a research test, the productivity of the PIV and acoustic measurements was surprisingly high, and was comparable to an industrial test program. The analyses of the acoustic data and the PIV data show indeed that the pylon wake interaction noise with the propeller can be successfully reduced, by means of controlled pylon blowing.

More details about this experiments can be found in the Refs. [3, 4]. scientific community. Especially, the large open-jet test section with the acoustic absorbing treatment on the tunnel is suitable for acoustic far-field measurements. Moreover, the $9.5 \times 9.5$ open-jet with Seifert wings offered the possibility to test a large-scale wind turbine model in a controlled test environment.

The test combined several objectives into one experiment, such that several test and measurement techniques were combined. Since, the wind tunnel configuration and setup for this experiment $(9.5 \times 9.5 \mathrm{~m}$ open-jet with Seifert 
wings) was uniquely used for the Mexico wind turbine rotor, special care had to be taken to verify the quality of the wind tunnel flow.

For this test, several measurements techniques were used:

- Flow measurements.

- Standard wind tunnel parameters.

- Pitot-static tube at wind tunnel centre-line.

- Pitot-static tube at PIV-plane.

- Model position.

- Angle of attack variations.

- Three components PIV technique.

- Static pressure at the collector.

- Out-of-flow microphone technique.

- Phased microphone array techniques.

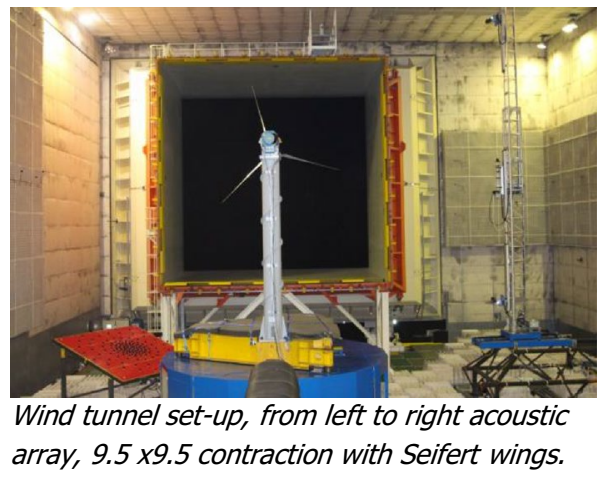

- DNW array technique installed upstream of the wind turbine rotor.

- Rotor performance measurements.

- Wind turbine loads (external balance).

- Torque (power adsorbed by the controller-brake).

- Blade pressure sensors (Kulites).

- RPM signals.

- Blade angles.

- Blade strain gauges (individual blade loads).

To achieve these measurements an international team was formed with the following members:

- Technical University of Denmark (DTU).

- Energy research Centre of the Netherlands (ECN).

- Technical University of Delft (The Netherlands).

- Technology Institute of Israel (Technion).
The data analyses indicate that the data are of high quality. All priority 1 test conditions have been measured, as well as some priority 2 and 3 test conditions. Independent verification of the wind tunnel calibration and wind turbine setup blockage effect, showed good agreement between pressure and PIV data, this establishing confidence in the wind tunnel calibration and simulation. Detailed flow fields have been recorded for future validation of CFD codes. Extensive acoustic data was gathered for validation of design codes. The overall comprehensive data set has been made available to the involved parties.

More details about these experiments can be found in the Refs. [5-9].

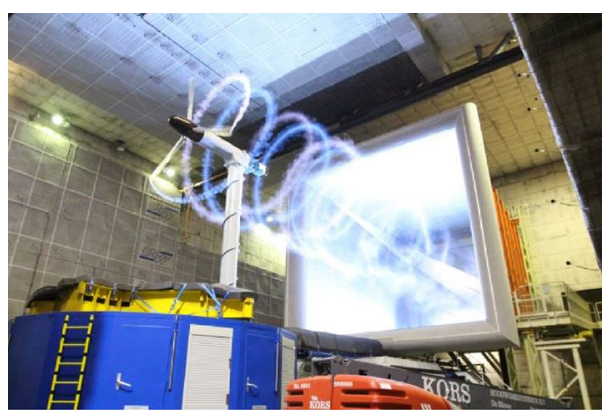

Visualisation of the wind turbine tip vortex, by means of smoke.

\subsection{Project for the ETW wind tunnel: time-resolved wake measurement of separated wing flow and wall interference investigations}

During the TNA test in the European Transonic Windtunnel ETW unique unsteady measurements of the wake flow field were performed, using time-resolved PIV and unsteady deformation measurements of an aircraft model in cruise configuration, at real-flight Reynolds and Mach numbers. These conditions were achieved by the combination of cryogenic temperatures and high stagnation pressures in ETW. The study was needed to further understand the occurring phenomena, and validate CFD codes (computational fluid dynamics).

The results of this scientific test gave valuable insights into the development and downstream propagation of wing wake flows, as well as the resulting effects on the empennage (tail). These scenarios are of great interest to the 
international aircraft industry, due to the potentially strong unsteadiness of separated wing flow at the edges of the flight envelope, that may lead to excitation of the empennage structure.

The main objectives of this test campaign were to perfume the following:

- Time-resolved PIV investigations of separated wing flow.

- Wall interference investigations.

- Acquisition of validation data for numerical calculations.

- Investigations of unsteady HTP inflow at stall conditions (low- and high-speeds).

- Buffet investigations at limits of the flight envelope.

- Acquisition of data to be compared with existing Common Research Model (CRM) wind tunnel data.

More than 40 international aerodynamic specialists from various European institutions, NASA (USA), TsAGI (Russia) and JAXA (Japan) met at ETW to attend the experimental test entry for the project "Time-resolved Wake Measurement of Separated Wing Flow and Wall Interference Investigations". The test was thoroughly prepared by means of computations to define the test requirements and to identify wake domains of interest [10].

The test was performed with a NASA CRM full-model [11], provided by NASA, and useable at cryogenic conditions. This model had been previously tested in the NASA NTF and Ames $11 \mathrm{ft}$. wind tunnels several times, and had also been used in the NASA Drag Prediction Workshop. For the CRM, a comprehensive data base is available in the public domain and this enabled a comparison to be made between ETW data and both, other wind tunnel data [12] and numerical calculations obtained by CFD [13]. For the testing of the NASA model, ETW designed and manufactured interface components to enable the mounting of the ETW Balance B004 and the AVS on the sting line.

One of the main objectives for this test was the visualisation of the vortices behind the wing, by means of PIV. Due to the nature of this high-speed separated flow, a new time-resolved PIV system was implemented in ETW, and operated by DLR Göttingen.

Among the large number of measurement techniques utilized, the following peculiarities should be pointed out:

- The model was well-equipped with 253 pressure taps on the wings, which were recorded by five scanners installed in the model nose.

- Markers for the Stereo Pattern Tracking (SPT) System were attached on both the port lower wing and HTP surface. Based on wind-off reference measurements over the entire incidence range of the model, the system could identify the displacement between loaded and unloaded conditions, which was then transformed into wing twist and bending information. For the illumination of the SPT markers, LED lights were installed at several positions in the test section.

- The model was mounted on the ETW-B004 six-component strain gauge balance.

- The model support system attached to the Model Cart 2 sting boss flange, comprised the conical stub sting incorporating the AVS anti-vibration unit. The new bent strut sting component was attached to the ETW stub sting, using a flange joint. The NASA Upper Swept Strut sting component was attached to the ETW bent strut using a conical joint, with setting screws.

- The model incidence and sideslip were derived from onboard instrumentation, combined with the Sector Roll System (SRS) instrumentation. The on-board instrumentation measured the angle between the model reference axis and the horizontal plane, irrespective of the model roll, pitch (and yaw) angles.

- The model attitude was measured directly by an on-board inclinometer, attached to the inclinometer bracket, which, in turn, was mounted to the balance adapter.

- A three-axis Entran accelerometer, installed within the model inclinometer heated package, was attached to the model adapter in the front fuselage, to monitor model dynamics. Two additional accelerometers were installed in the fuselage nose, and in the rear fuselage, to provide additional information on the model dynamic characteristics.

The actual test was conducted at Mach numbers in the range of $0.25-0.87$, and at Reynolds numbers between 2.9 and 30.0 million. The tunnel temperature varied between 300 and $115 \mathrm{~K}$, and stagnation pressure levels from 111 to $445 \mathrm{kPa}$ were set. The time-resolved PIV measurements were performed by DLR Göttingen at fixed model incidences. Furthermore, detailed wall interference measurements were conducted and compared with computations [14].

The test results were made available to the involved scientists, and constitute an extensive amount of data for validation of computational methods. The PIV results achieved both at sub- and transonic stall conditions, show turbulent flow structures in the wake of the wing, which provide an insight into turbulent energies and frequency spectra. For the first time, time-resolved PIV measurements with a temporal resolution of $1 \mathrm{kHz}$, have been successfully carried out at such high, flight-relevant Reynolds numbers [15]. The test data has allowed the characterization of the unsteady development of massively separated wing flows, and how the wake development progresses towards the empennage. The test data have also been compared with complex numerical 
simulations, considering aeroelastic wing deformationn [16-18].

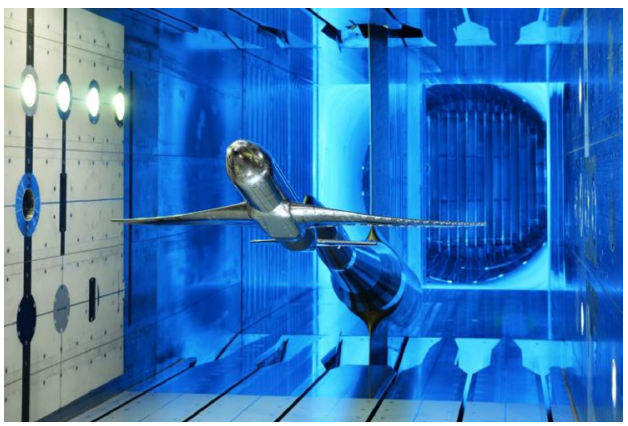

The CRM model mounted in the ETW test section during ESWIRP TNA test

\section{Conclusion}

One of the ACARE activities was to identify the strategic research capabilities and infrastructure needed to assure continued European leadership in aeronautics for the future. Three wind tunnels, the DNW-LLF, the ETW and the ONERA-S1MA have been identified as part of the strategic infrastructure, to ensure the future of European aeronautical research and industrial development. With this endorsement from ACARE, further steps toward Europeanization of research access and facility development have been taken.

The operators of the aforementioned three facilities have formed a consortium to jointly further the capabilities of their experimental research facilities, and to provide valuable wind tunnel access to the academic research community. Within the EU-FP7 ESWIRP project (European Strategic Wind tunnels Improved Research Potential), upgrades were performed, combining the support from the European Commission with national funds. Furthermore, successful research groups from a range of European academic institutions were provided with EC-funded access to these updated capabilities, ito perform large-scale scientific experiments. More than 100 scientists from 17 different nations including Russia, USA and Japan made use of this opportunity. The research undertaken ranged from fundamental turbulence studies, to the influence of high Reynolds number boundary layers on aircraft performance, through to rotor performance under difficult flight conditions.

Common to all the TNA academic projects, high-quality and previously unattainable experimental data were generated for research. Hence, ESWIRP has enabling researchers and graduate students to further the development of their own scientific tools for the good of the aerospace community, and the verification of those tools using publicly available benchmark data.
Acknowledgements The author wish to acknowledge the European Commission for the financial support of the ESWIRP Project within the 7th Research Framework Program of the European Union (Grant Agreement no: FP7-227816).

\section{References}

1. Hermans, C., Hegen, S.: DNW innovations in wind tunnel testing: new moving belt system for large low speed facility. CEAS Aeronaut. J. (2018). https://doi.org/10.1007/s13272-018-0285-4

2. Barois, T., Baudet, C., Bourgoin, M., Mordant, N., Vandenberghe, T., Sumbekova, S., Stelzenmuller, N., Aliseda, A., Gibert, M., Roche, P., Volk, R., Lopez, M., Chevillard, L., Fiabane, L., Delville, J., Fourment, C., Bouha, A., Danaila, L., Bodenschatz, E., Bewley, G., Sinhuber, M., Segalini, A., Orlu, R., Torrano, I., Mantik, J., Guariglia, D., Uruba, V., Skala, V., Puczylowski, J., Peinke, J.: Investigation of the small scale statistics of turbulence in the Modane S1MA wind-tunnel. CEAS Aeronaut. J. (2015)

3. Sinnige, T., Ragni, D., Malgoezar, A.M.N., Eitelberg, G., Veldhuis, L.L.M.: APIAN-INF: an aerodynamic and aeroacoustic investigation of pylon-interaction effects for pusher propellers. CEAS Aeronaut. J. (2017). https://doi.org/10.1007/s 1327 2-017-0247-2

4. Sinnige, T., Ragni, D., Eitelberg, G., Veldhuis, L.L.M.: Mitigation of pusher-propeller installation effects by pylon trailing-edge blowing. J. Aircr. 54(1), 292-300 (2017)

5. Boorsma, K., Schepers, J.G.: Rotor experiments in controlled conditions continued: new Mexico. J. Phys. Conf. Ser. 753, 022004 (2016)

6. Sørensen, N.N., et al.: CFD computations of the second round of MEXICO rotor measurements. J. Phys. Conf. Ser. 753, 022054 (2016)

7. Boorsma, K., Schepers, J.G.: Rotor experiments in controlled conditions continued: New Mexico. ECN (Energy research Centre of the Netherlands) publication, Reference ECN-M-16-063 EN October 2016

8. Parra, E.A., Boorsma, K., Schepers, J.G., Snel, H.: Momentum considerations on the New MEXICOexperiment. ECN (Energy research Centre of the Netherlands) publication, Reference ECNM-16-064 EN October 2016

9. Sorensen, N.N., Zahle, F., Boorsma, K., Schepers, J.G.: CFD computations of the second round of MEXICO rotor measurements. ECN (Energy research Centre of the Netherlands) publication, Reference ECN-M-16-067 EN October 2016

10. Lutz, T., Gansel, P.P., Godard, J.-L., Gorbushin, A., Konrath, R., Quest, J., Rivers, M.B.: Going for Experimental and Numerical Unsteady Wake Analyses Combined with Wall Interference Assessment, by Using the NASA CRM-Model in ETW, 51st AIAA Aerospace Sciences Meeting. AIAA Paper 2013-0871, January 2013

11. Vassberg, J., Dehaan, M., Rivers, M., Wahls, R.: Development of a Common Research Model for Applied CFD Validation Studies, 26th AIAA Applied Aerodynamics Conference, AIAA Paper 2008-6919, August 2008

12. Rivers, M., Quest, J., Rudnik R.: Comparison of the NASA common research model european transonic wind tunnel test data to NASA national transonic facility test data. CEAS Aeronaut. J. (2017). https://doi.org/10.1007/s13272-017-0250-7

13. Vrchota, P., Prachař, A.: Using wing model deformation for improvement of CFD results of ESWIRP project. CEAS Aeronaut. J. (2018). https://doi.org/10.1007/s13272-018-0286-3

14. Kursakov, I.A., Gorbushin, A.R., Bosnyakov, S.M., Glazkov, S.A., Lysenkov, A.V., Matyash, S.V., Semenov, A.V., Quest, J.: 
A numerical approach for assessing slotted wall interference using the CRM model at ETW. CEAS Aeronaut. J. (2017)

15. Konrath, R., Geisler, R., Agocs, J., Ehlers, H., Philipp, F., Quest, J.: High-speed PIV applied to wake of NASA CRM model at high Re-number sub- and transonic stall conditions. CEAS Aeronaut. J. (2017)

16. Lutz, T., Gansel, P.P., Waldmann, A., Zimmermann, D.-M., Schulte am Hülse, S.: Prediction and measurement of the common research model wake at stall conditions. J. Aircr. 53(2), 501-514 (2016)

\section{Affiliations}

\section{Guy Boyet ${ }^{1}[$ (]}

$\triangle$ Guy Boyet guy.boyet@onera.fr
17. Zimmermann, DM., Waldmann, A., Lutz, T. et al.: Development of flow structures in the near-field wake region of the common research model. CEAS Aeronaut. J. (2016). https://doi. org/10.1007/s13272-016-0222-3

18. Waldmann, A., Gansel, P.P., Lutz, T., Krämer, E.: Unsteady wake of the NASA common research model in low-speed stall. J. Aircr. 53(4), 1073-1086 (2016)
1 Centre de Palaiseau, ONERA-Wind Tunnel Division, BP 80100, 91123 Palaiseau Cedex, France 